\title{
A STUDY ABOUT THE POWER FLOW IN BRUSHLESS DOUBLY FED ASYNCHRONOUS GENERATORS FOR WIND POWER SYSTEMS
}

\author{
${ }^{1}$ Hélio Voltolini, ${ }^{2}$ Renato Carlson, ${ }^{3}$ Fredemar Rüncos \\ ${ }^{1}$ CEFET/PR - ${ }^{2}$ GRUCAD/UFSC - ${ }^{3}$ WEG S.A. \\ ${ }^{1}$ Av. Monteiro Lobato, km 4, Ponta Grossa, PR \\ ${ }^{2}$ Campus Universitário, Trindade, 88040-900, Florianópolis, SC, BRAZIL \\ ${ }^{3}$ C.P. 3000, 89250-900, Jaraguá do Sul, SC, BRASIL \\ 1helio@grucad.ufsc.br, ${ }^{2}$ rcarlson@ieee.org, ${ }^{3}$ fredemar@weg.com.br
}

\begin{abstract}
This paper presents dynamic modeling and simulation of Brushless Doubly Fed Induction Generator (BDFIG) as an alternative for variable speed wind power applications. The mathematic models of active and reactive power for BDFIG have been developed. The power control systems of a $75 \mathrm{kVA}$ generator and wind turbine were simulated in Matlab/Simulink/SymPower Systems. The generator's control system is based on vector control principles which enable to decouple active and reactive power control. The power flow in the two stator windings and in the grid is analyzed in two different power factor correction schemes. The results presented show that the rating of the two converters used in this system can be calculated considering that both converters are compensating reactive power. It allows a reduction of the kVA rating of the auxiliary-side converter.
\end{abstract}

Keywords - brushless doubly fed induction generator, vector control, wind power, variable speed generator.

\section{INTRODUCTION}

Doubly fed induction machines with a wounded rotor have been used as variable speed electric generator especially in wind power generators systems [1]. This type of generator have been controlled with power converters with reduced power rating when compared with the machine electrical power output. The stator winding is connected to the electrical mains and the rotor winding is connected to a bidirectional static power converter through slip-rings. The presence of slip rings reduces the life time of the machine and increases the maintenance costs. An alternative to overcome this drawback is the brushless doubly fed induction generator (BDFIG) [2-6]. The BDFIG has its origins in the technology of cascade induction machines and consists in two three-phase windings with different number of pole pairs in the stator and a special rotor cage. The power and the auxiliary windings are connected to the three-phase power supply; the power winding is connected directly while the auxiliary winding is connected through an AC/DC/AC bidirectional static power converter. In this configuration, as is the case for the doubly-fed induction machine with brushes, the converter rating required is only the slip-fraction of the machine capacity and with the appropriate control, the active and reactive power can be regulated above and bellow the

Manuscript received on May 31, 2005; first revision on August 30, 2005; second revision on February 12, 2006. Recommended by the Editor of the Special Section Edson H. Watanabe. synchronous speed of the machine. [3-15]. A general scheme of the brushless doubly fed asynchronous generator is shown in Fig. 1.

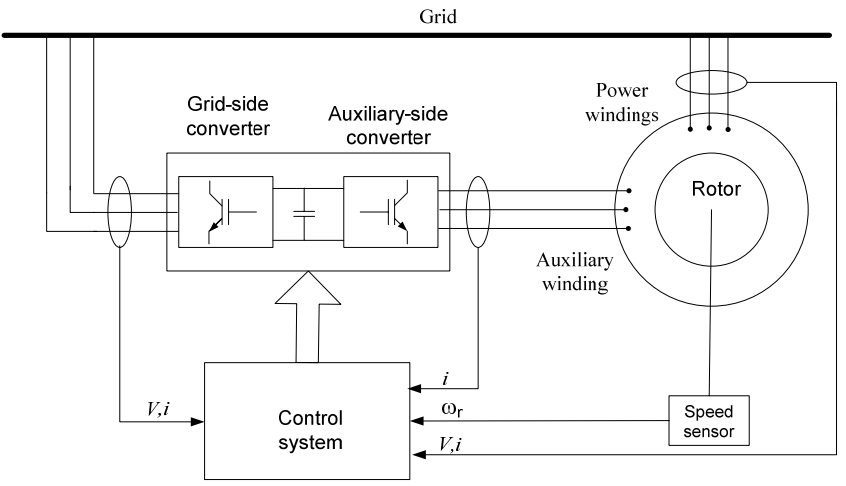

Fig. 1. Brushless doubly fed asynchronous generator

The major interest is the operation in synchronous mode. The synchronous operation occurs when the two stator windings share a rotor current of the same frequency. The synchronous operation requires that the auxiliary winding frequency be adjusted to every rotor speed. There is no alternative of operation which is not the synchronous one, because otherwise the machine could not operate smoothly due to the torque pulsation generated by the auxiliary winding.

In the synchronous mode, the cross-coupling between auxiliary and power windings is only guaranteed if both windings induce equal rotor frequencies:

$$
\omega_{r p}=\omega_{r a}
$$

where:

$$
\begin{gathered}
\omega_{p}=\omega_{r p}+p_{p} \omega_{r} \\
\omega_{a}=-\omega_{r a}+p_{a} \omega_{r}
\end{gathered}
$$

In (2) and (3), $\omega_{\mathrm{r} p}$ and $\omega_{\mathrm{ra}}$ are the induced rotor frequencies for power and auxiliary windings, $\omega_{p}$ and $\omega_{a}$ are the power and auxiliary frequencies, $\omega_{r}$ is the rotor speed, $\mathrm{p}_{p}$ and $\mathrm{p}_{a}$ are the pole-pair of the power and auxiliary windings.

The synchronous mode is guaranteed if the converter imposes frequency $\omega_{a}$ given by:

$$
\omega_{a}=\left(p_{p}+p_{a}\right) \omega_{r}-\omega_{p}
$$

\section{THE MACHINE MODEL}

In this paper all mathematical models were developed considering the synchronous mode. In the BDFG, the power windings is directly connected to utility grid, hence the level 
of power winding flux remains approximately constant. Thus, the choice of the power windings flux as orientation reference frame is a good option. The frame $d q_{p}$ is aligned with the power winding flux and rotates at $\omega_{e}$ (speed of the flux in the power winding). The frame $d q_{r}$, fixed to the rotor, rotates at $p_{p} \omega_{r}$ relative to the frame $d q_{p}$ and the frame $d q_{a}$, fixed to the auxiliary winding, rotates at $\left(p_{p}+p_{a}\right) \omega_{r}$ relative to frame $d q_{p}$.

The machine's dq voltage equations in the synchronous reference frame are:

$$
\begin{gathered}
v_{q p}=r_{p} i_{q p}+\omega_{e} \lambda_{d p}+\frac{d \lambda_{q p}}{d t} \\
v_{d p}=r_{p} i_{d p}+\omega_{e} \lambda_{q p}+\frac{d \lambda_{d p}}{d t} \\
v_{q r}=0=r_{r} i_{q r}+\left(\omega_{e}-p_{p} \omega_{r}\right) \lambda_{d r}+\frac{d \lambda_{q r}}{d t} \\
v_{d r}=0=r_{r} i_{d r}+\left(\omega_{e}-p_{p} \omega_{r}\right) \lambda_{q r}+\frac{d \lambda_{d r}}{d t} \\
v_{q a}=r_{a} i_{q a}+\left[\omega_{e}-\left(p_{p}+p_{a}\right) \omega_{r}\right] \lambda_{d a}+\frac{d \lambda_{q a}}{d t} \\
v_{d a}=r_{a} i_{d a}+\left[\omega_{e}-\left(p_{p}+p_{a}\right) \omega_{r}\right] \lambda_{q a}+\frac{d \lambda_{d a}}{d t}
\end{gathered}
$$

where:

$$
\begin{gathered}
\lambda_{q p}=L_{p} i_{q p}+L_{m p} i_{d r} \\
\lambda_{d p}=L_{p} i_{d p}+L_{m p} i_{q r} \\
\lambda_{d r}=L_{r} i_{d r}+L_{m p} i_{d p}-L_{m a} i_{d a} \\
\lambda_{q r}=L_{r} i_{q r}+L_{m p} i_{q p}-L_{m a} i_{q a} \\
\lambda_{q a}=L_{a} i_{q a}-L_{m a} i_{q r} \\
\lambda_{d a}=L_{a} i_{d a}-L_{m a} i_{d r}
\end{gathered}
$$

The total electromagnetic torque is expressed as:

$$
\begin{gathered}
T_{e}=T_{e p}+T_{e a} \\
T_{e}=\frac{3}{2} p_{p} L_{m p}\left(i_{q p} i_{d r}-i_{d p} i_{q r}\right)+\frac{3}{2} p_{a} L_{m a}\left(i_{q a} i_{d r}-i_{d a} i_{q r}\right)
\end{gathered}
$$

The subscripts $p, a$ and $r$ refer to power winding, auxiliary winding and rotor winding quantities.

\section{THE GRID-SIDE CONVERTER}

The grid-side PWM voltage fed converter is connected to the grid by three single-phase chokes (Fig. 2). With this configuration it is possible to operate using boost mode and have attractive features as constant dc bus voltage, low harmonic distortion of grid current, bidirectional power flow and adjustable power factor. The main objective of the gridside converter is to keep the DC-link voltage constant regardless the magnitude and direction of the auxiliary winding power. However it can also be involved in the power factor regulation.

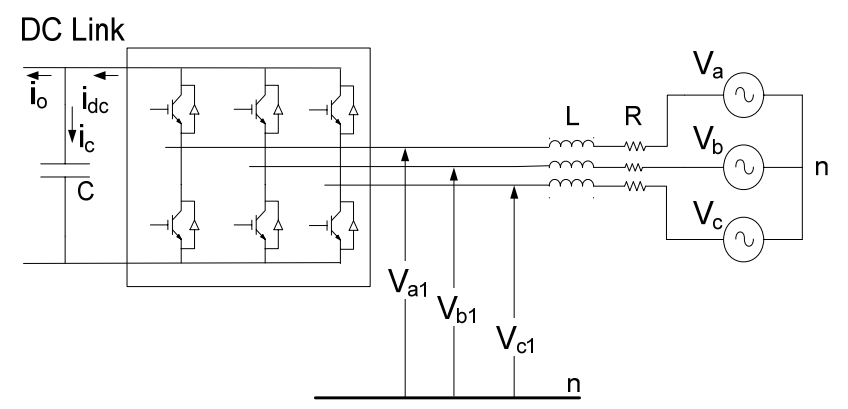

Fig. 2. Grid-side converter configuration.

The grid-side converter control is based on the $d q$ voltage equations of the grid-reactance-converter system represented in Fig. 2 expressed as:

$$
\begin{aligned}
& v_{q e}=R i_{q e}+L \frac{d i_{q e}}{d t}+\omega_{e} L i_{d e}+v_{q 1} \\
& v_{d e}=R i_{d e}+L \frac{d i_{d e}}{d t}+\omega_{e} L i_{q e}+v_{d 1}
\end{aligned}
$$

where $L$ and $R$ are the inductance and resistance of the chokes, respectively, $v_{q e}, v_{d e}, i_{q e}, i_{d e}$ are the mains voltages and currents in the $d q$ reference frame, $v_{q 1}$ and $v_{d 1}$ are the ac side voltages of the converter in $d q$ reference frame and $\omega_{e}$ is the angular frequency of the grid.

The vector control approach is used, with a reference frame oriented along the grid voltage phasor $\left(V_{e}\right)$ position, such that $v_{d e}=V_{e}$ and $v_{q e}=0$. This enables independent control of the active and reactive power through the $i_{d e}$ and $i_{q e}$, respectively [1]. The DC link voltage can be controlled by the active power flow between the two converters in the range of $20 \%$ to $30 \%$ above the peak value of the grid voltage. In this paper, the DC link voltage was regulated at $800 \mathrm{~V}$ for a grid voltage of $440 \mathrm{~V}$.

Fig. 3 shows the scheme of the grid-side converter and its controls as simulated in Matlab/Simulink/SimPower Systems.

\section{AUXILIARY-SIDE CONVERTER}

The aim of the auxiliary-side converter is to impose a current to the auxiliary winding and control independently the active and reactive power in the power winding. Fig 5 shows the control scheme based on the cascade regulation method.

The power winding of the BDFIG is directly connected to a utility power supply; hence the level of power winding flux remains approximately unchanged. Thus, the choice of the power winding flux as the orientation reference frame is a reasonable option. In order to get satisfying control performance, power winding flux oriented control method has been presented, in which the d-axis of power winding synchronous reference frame is aligned with power winding flux, i.e. the axis $d_{p}$ is aligned with the power windings flux $\lambda_{p}$, such that: 


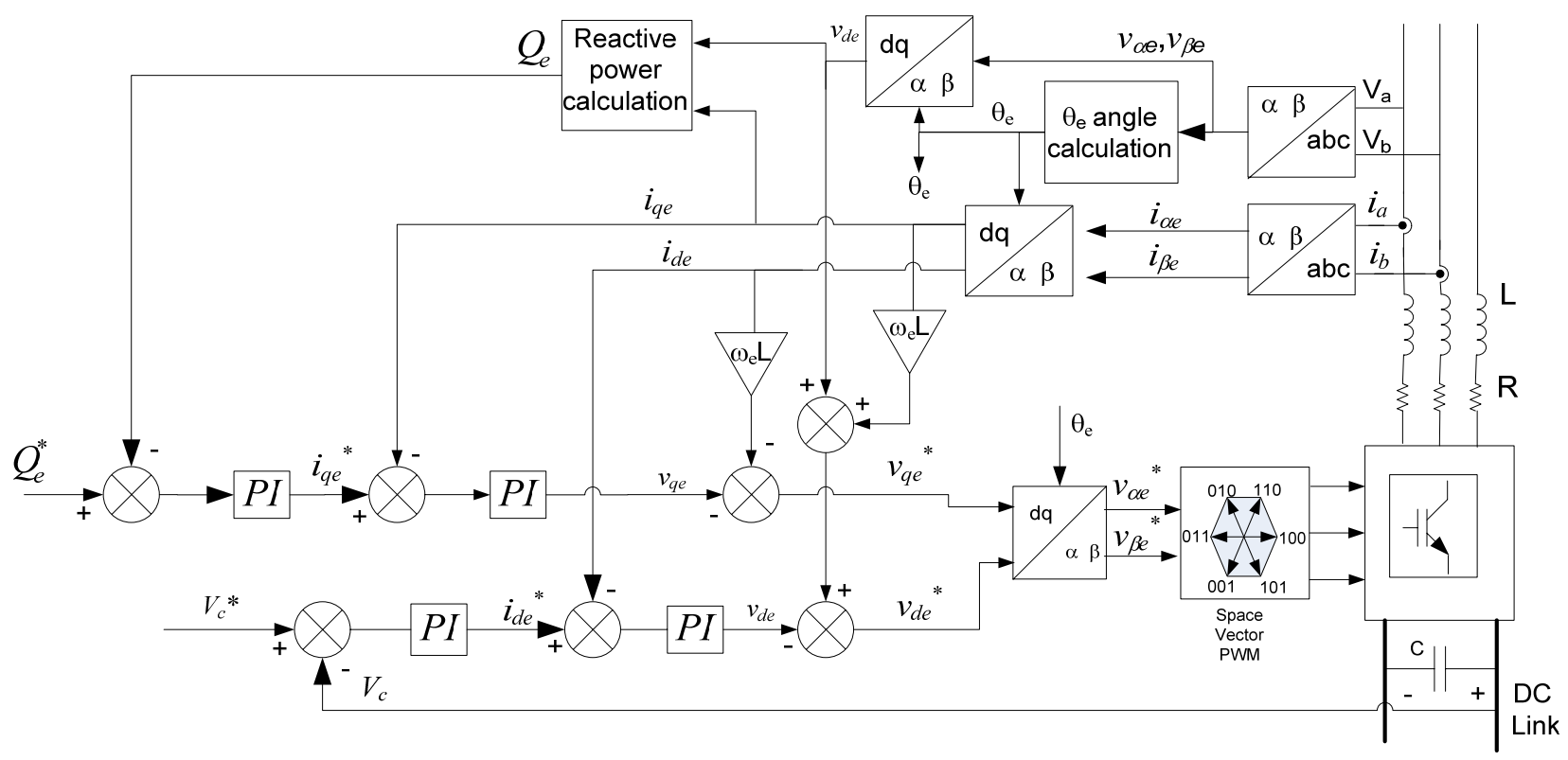

Fig. 3. Control system for the grid-side converter.

$$
\begin{gathered}
\lambda_{d p}=\lambda_{p} \\
\lambda_{q p}=0
\end{gathered}
$$

The magnitude and position of the power windings flux is calculated by the voltage and current in the $\alpha \beta$ axes and is expressed by:

$$
\begin{aligned}
& \lambda_{\alpha p}=\int\left(V_{\alpha p}-R_{p} i_{\alpha p}\right) d t \\
& \lambda_{\beta p}=\int\left(V_{\beta p}-R_{p} i_{\beta p}\right) d t
\end{aligned}
$$

The integration of the above equations produces an error associated with the implementation of the integrator that is constant and appears somehow like an offset in the initial integrated value. [17].

To avoid this problem, these two equations were implemented as shown in Fig. 4. The integrator can be implemented as a numerical integrator for application in a discrete time system. The output dc component was compensated in the integrator input by a gain. This gain defines the velocity of the error compensation. For a sampling time $T_{s}$ of $2 \mu$ s the feedback gain was chosen equal to 100.

From these two flux components the power winding flux position can be calculated:

$$
\theta_{p}=\tan ^{-1}\left(\lambda_{\beta p} / \lambda_{\alpha p}\right)
$$

The auxiliary winding variables are synchronized to the position of the power winding variables by the angle $\theta_{a}$ given by:

$$
\theta_{a}=\left(p_{p}+p_{a}\right) \theta_{r}-\theta_{p}
$$

According to equations (5) to (16), and the orientation realized with equations (21) and (22), the dynamic relation between the auxiliary winding and power winding currents is:

$$
\begin{aligned}
& \frac{d}{d t} i_{q a}=-\frac{L_{p} r_{r}}{L_{m p} L_{m a}} i_{q p}-\frac{\sigma L_{r} L_{p}}{L_{m p} L_{m a}} \frac{d}{d t} i_{q p}-\omega_{1} i_{d a} \\
& -\frac{\sigma L_{r} L_{p}}{L_{m p} L_{m a}} \omega_{1} i_{d p}+\frac{L_{r}}{L_{m p} L_{m a}} \omega_{1} \lambda_{p} \\
& \frac{d}{d t} i_{d a}=-\frac{L_{p} r_{r}}{L_{m p} L_{m a}} i_{d p}-\frac{\sigma L_{r} L_{p}}{L_{m p} L_{m a}} \frac{d}{d t} i_{d p}+\omega_{1} i_{q a} \\
& +\frac{\sigma L_{r} L_{p}}{L_{m p} L_{m a}} \omega_{1} i_{q p}+\frac{L_{r}}{L_{m p} L_{m a}} \frac{d}{d t} \lambda_{p}
\end{aligned}
$$

where:

$$
\begin{gathered}
\omega_{1}=\omega_{e}-p_{p} \omega_{r} \\
\sigma=1-\frac{L_{m p}^{2}}{L_{p} L_{r}}
\end{gathered}
$$

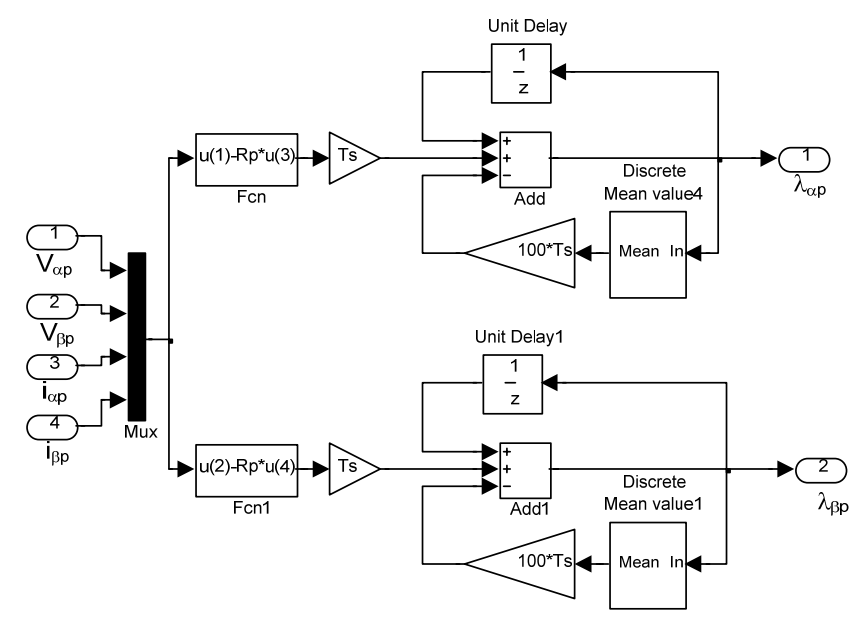

Fig. 4. Implementation of the flux estimator in Matlab/Simulink/SymPowerSystems. 


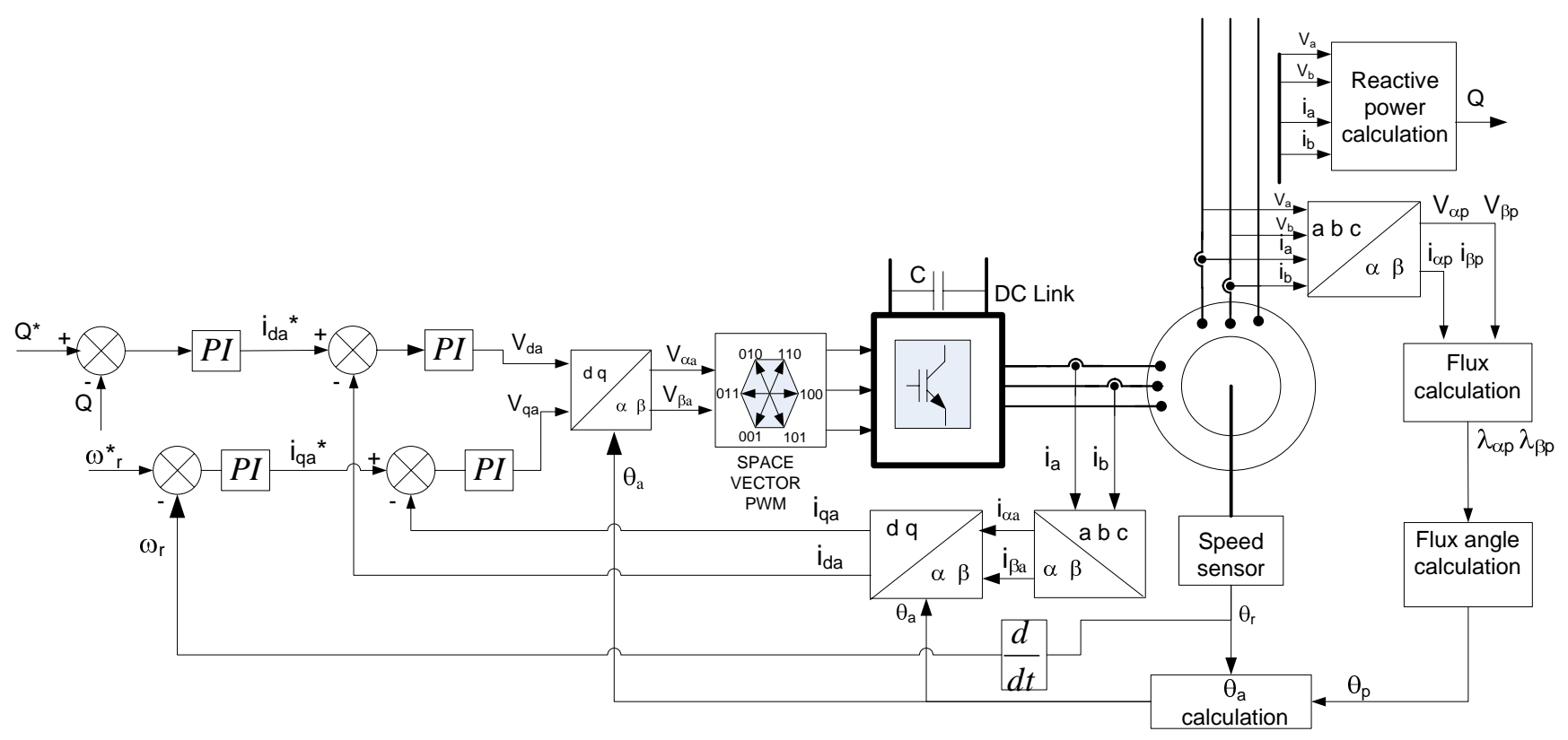

Fig. 5. Control system for auxiliary-side converter

The first two terms on the right side of equations (27) and (28) define the direct relation between the auxiliary and power windings currents. The other components reflect the $d q$ cross coupling and the influence of the speed $\omega_{1}$.

The control of the auxiliary windings current is realized through a PWM voltage source converter, and the dynamic equations derived from (5) to (16), (21), (22), (27) and (28) are:

$$
\begin{aligned}
& v_{q a}=r_{a} i_{q a}+\left(L_{a}-\frac{L_{m a}^{2}}{\sigma L_{r}}\right) \frac{d}{d t} i_{q a}-\frac{L_{m a} L_{p} r_{r}}{L_{m p} L_{r} \sigma} i_{q p} \\
& +\left[\omega_{1}\left(L_{a}-\frac{L_{m a}^{2}}{\sigma L_{r}}\right)-P_{a} \omega_{r} L_{a}\right] i_{d a}-P_{a} \omega_{r} \frac{L_{m a} L_{p}}{L_{m p}} i_{d p} \\
& +\left[\frac{\omega_{1}(1-\sigma)}{\sigma}+P_{a} \omega_{r}\right] \frac{L_{m a}}{L_{m p}} \lambda_{p} \\
& v_{d a}=r_{a} i_{d a}+\left(L_{a}-\frac{L_{m a}^{2}}{\sigma L_{r}}\right) \frac{d}{d t} i_{d a}-\frac{L_{m a} L_{p} r_{r}}{L_{m p} L_{r} \sigma} i_{d p} \\
& +\left[\omega_{1}\left(\frac{L_{m a}^{2}}{\sigma L_{r}}-L_{a}\right)+P_{a} \omega_{r} L_{a}\right] i_{q a}-P_{a} \omega_{r} \frac{L_{m a} L_{p}}{L_{m p}} i_{q p} \\
& +\frac{L_{m a} r_{r}}{L_{m p} L_{r} \sigma} \lambda_{p}
\end{aligned}
$$

Equations (31) and (32) contain $d q$ cross coupling and others terms which can be compensated by the PI controller in each axis.

There are two independent loops that control the active and reactive power windings by means $i_{q a}$ and $i_{d a}$, respectively.

The general form of active and reactive power are:

$$
\begin{gathered}
P_{p}=\frac{3}{2}\left(v_{q p} i_{q p}+v_{d p} i_{d p}\right) \\
Q_{p}=\frac{3}{2}\left(v_{q p} i_{d p}-v_{d p} i_{q p}\right)
\end{gathered}
$$

Substituting equations (5) to (16), (21) and (22) into equations (33) and (34), the power winding active and reactive power are affected by the $i_{q a}$ and $i_{d a}$ current component, respectively as:

$$
\begin{gathered}
P_{p}=\frac{3}{2} \frac{\omega_{e}}{\sigma L_{r} L_{p}}\left(-\frac{r_{r}}{\omega_{1}} \lambda_{p}^{2}-L_{m p} L_{m a} \lambda_{p} i_{q a}\right) \\
Q_{p}=\frac{3}{2} \frac{\omega_{e} \lambda_{p}}{\sigma}\left(-\frac{r_{r}}{L_{r} \omega_{1}} i_{q p}+\frac{1}{L_{p}} \lambda_{p}-\frac{L_{m p} L_{m a}}{L_{r} L_{p}} i_{d a}\right)
\end{gathered}
$$

The active power $P_{p}$ and reactive power $Q_{p}$ can be controlled by adjusting the auxiliary winding currents $i_{q a}$ and $i_{d a}$, respectively.

A proportional-integral (PI) regulator is used to reduce the variables error to zero. Due to the transformations used, all variables are DC quantities, that eliminates steady-state error and simplify the project of the controllers.

The space vector PWM was mathematically implemented in the model according to [12] and will not be detailed in this paper.

According the block diagram of the auxiliary-side converter control represented in Fig. 5 the active power command acts on the speed regulator and the reactive power command acts on the $i_{d a}$ current and can be manipulated by the system's operator.

\section{SIMULATION RESULTS}

The whole system was simulated in three points of operation. In wind power systems that operate in variable 
speed, a speed range of $\pm 30 \%$ around the synchronous speed is acceptable. For the generator considered (see Appendix) the rotor speed of $252 \mathrm{rpm}, 360 \mathrm{rpm}$ and $468 \mathrm{rpm}$ were chosen to take measurements of active and reactive power at the power winding, the auxiliary winding and the system output (grid).

A wind turbine was used in the simulation as the source of torque for the generator and the generator rotor speed was controlled in each of those three points mentioned above. The active and reactive powers values, as represented in Fig. 6 , are presented in table I.

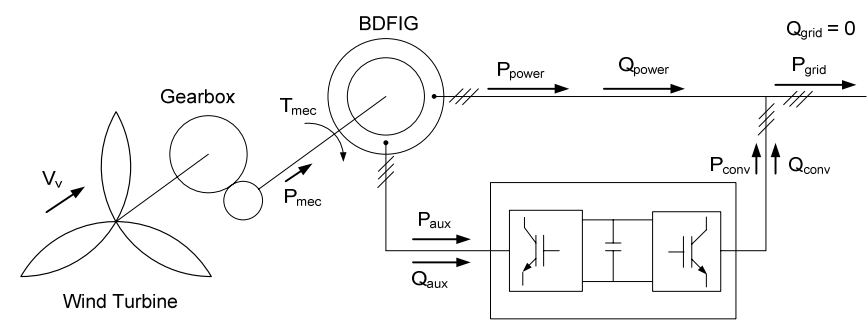

Fig. 6. Representation of the power flow of the simulated system.

TABLE I

Power Flow in the System

\begin{tabular}{|c|c|c|c|c|c|c|c|c|}
\hline $\begin{array}{c}\text { Wind } \\
\text { speed } \\
\text { (m/s) }\end{array}$ & $\begin{array}{c}\text { Pmec } \\
\text { (kW) }\end{array}$ & $\begin{array}{c}\text { Ppower } \\
\text { (kW) }\end{array}$ & $\begin{array}{c}\text { Qpower } \\
\text { (kVAr) }\end{array}$ & $\begin{array}{c}\text { Paux } \\
\text { (kW) }\end{array}$ & $\begin{array}{c}\text { Qaux } \\
\text { (kVAr) }\end{array}$ & $\begin{array}{c}\text { Pconv } \\
\text { (kW) }\end{array}$ & $\begin{array}{c}\text { Qconv } \\
\text { (kVAr) }\end{array}$ & $\begin{array}{c}\text { Pgrid } \\
\text { (kW) }\end{array}$ \\
\hline 6.5 & 11.6 & 16.4 & 19.5 & -6.2 & -21.8 & -6.8 & -19.5 & 9.7 \\
\hline 9.2 & 33.8 & 33.4 & 22.1 & -1.3 & 0 & -1.8 & -22.1 & 31.6 \\
\hline $\begin{array}{c}12 \\
\text { (case 1) }\end{array}$ & 75.0 & 56.4 & 22.2 & 15.6 & 24.1 & 15.0 & -22.2 & 71.4 \\
\hline $\begin{array}{c}12 \\
\text { (case 2) }\end{array}$ & 75.0 & 56.1 & 0 & 14.8 & 33.7 & 14.2 & 0 & 70.4 \\
\hline
\end{tabular}

For the $12 \mathrm{~m} / \mathrm{s}$ wind speed, two situations are considered. In the first one, both auxiliary and grid-side converters are participating in the grid power factor regulation. In the second one, the auxiliary-side converter is controlling the grid power factor while the grid side converter is only maintaining constant the DC link voltage.

From Table I it is clear that when both converters are compensating reactive power (case 1 ) the $\mathrm{kVA}$ rating of both converters is comparable:

$$
S_{\text {aux }}=28.7 \mathrm{kVA} \approx S_{\text {conv }}=26.8 \mathrm{kVA}
$$

In case 2 , the $\mathrm{kVA}$ rating of the grid-side converter is lower than the auxiliary-side one:

$$
S_{\text {aux }}=36.8 \mathrm{kVA} \neq S_{\text {conv }}=14.2 \mathrm{kVA}
$$

It has to be observed that in case 1 the efficiency of the whole energy conversion chain is a little higher (95.2 \%) than in case 2 (93.9\%). This conclusion does not consider the generator iron losses as well as mechanical losses. The estimated losses for the brush and the brushless generators of the same power are presented in Table II. It is evident from these data that there is an increase in both the iron and the mechanical losses in the brushless machine. But a real comparison of the respective efficiencies should take into account the reduction in long term maintenance due to the elimination of the brushes.
TABLE II

Power losses in the brush and the brushless induction

\begin{tabular}{|c|c|c|c|c|}
\hline \multirow[b]{2}{*}{$P_{\text {joule1 }}(k W)$} & \multicolumn{2}{|c|}{$\begin{array}{c}\text { DFIG } \\
75 \mathrm{~kW}-360 \mathrm{rpm}\end{array}$} & \multicolumn{2}{|c|}{$\begin{array}{l}\text { Brushless DFIG } \\
75 \mathrm{~kW}-360 \mathrm{rpm}\end{array}$} \\
\hline & 5.13 & $58.88 \%$ & 3.22 & $43.7 \%$ \\
\hline$P_{\text {joule2 }}(\mathrm{kW})$ & 0.95 & $10.90 \%$ & 2.82 & $38.30 \%$ \\
\hline $\mathbf{P}_{\text {iron }}(\mathrm{kW})$ & 1.17 & $13.40 \%$ & 0.51 & $6.90 \%$ \\
\hline$P_{s}(k W)$ & 0.72 & $8.22 \%$ & 0.41 & $5.60 \%$ \\
\hline$P_{\text {mec }}(\mathrm{kW})$ & 0.75 & $8.60 \%$ & 0.41 & $5.50 \%$ \\
\hline$P_{\text {total }}(k W)$ & 8.72 & $100 \%$ & 7.37 & $100 \%$ \\
\hline
\end{tabular}
generator systems

In table II, subscripts 1 and 2 refer to stator and rotor, respectively.

Only in case 2 , the current $i_{q e}$ of the grid-side converter is adjusted to zero. In all other points the current $i_{q e}$ is adjusted as:

$$
i_{q e}=\sqrt{i_{q a}^{2}+i_{d a}^{2}-i_{d e}^{2}}
$$

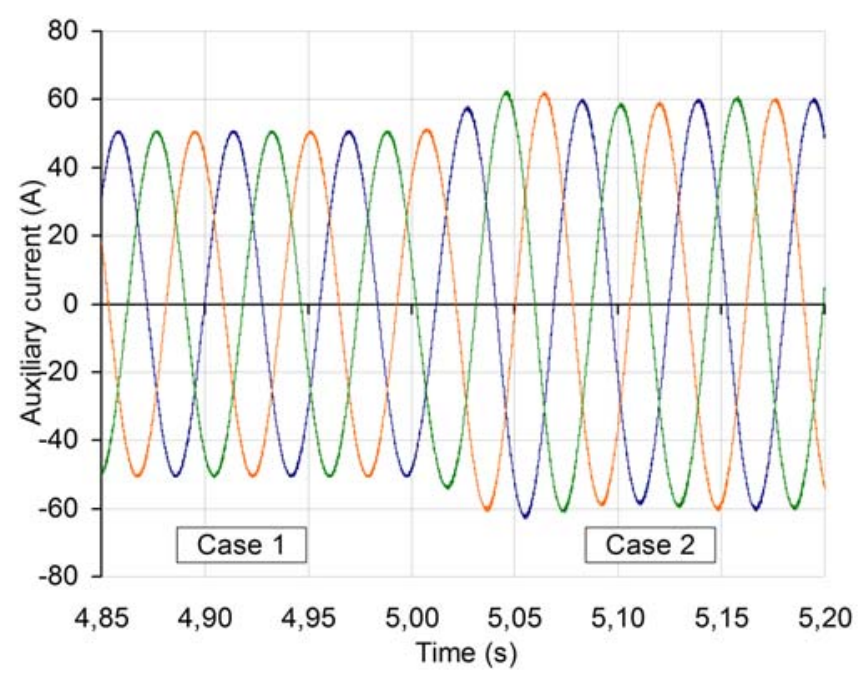

Fig. 7. Auxiliary winding currents for case 1 and 2.

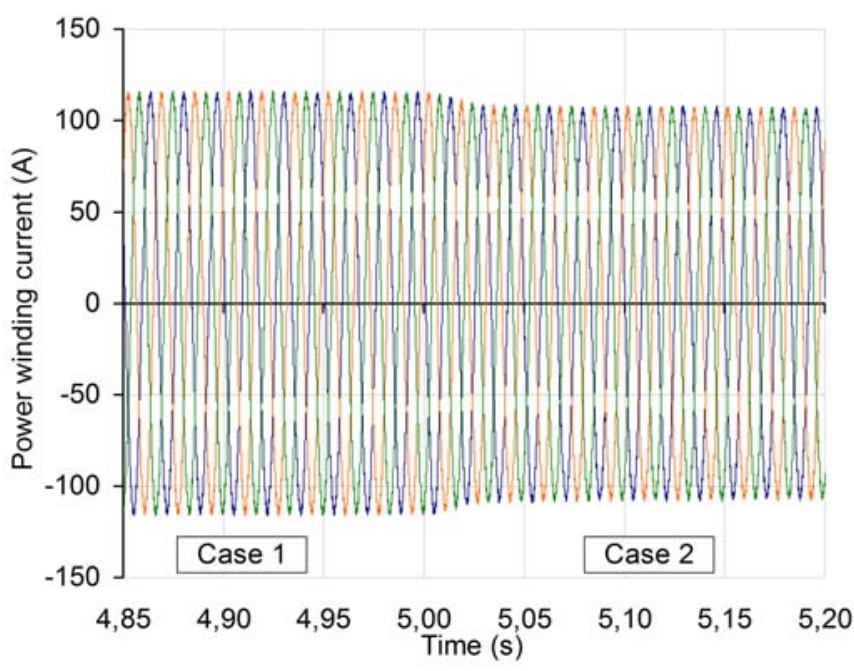

Fig. 8. Power winding current for case 1 and 2.

Figs. 7, 8 and 9 show the currents in auxiliary winding, power winding and in the grid-side converter, respectively 
for cases 1 and 2 . The current $i_{q}$ of the auxiliary-side converter is maintained in accordance with Eq. (18) and in $t=5$ s current $i_{q}$ is zero. It can be observed that, from case 1 to case 2 , the current in the auxiliary winding decreases and the current in the grid-side converter increases. Fig. 7 shows that in case 1, the current manipulated by auxiliary-side converter is smaller than in case 2. As is shown in Fig. 9, the grid-side converter current for case 1 equals the one of the auxiliary-side converter. Thus, two converters can be projected for same power.

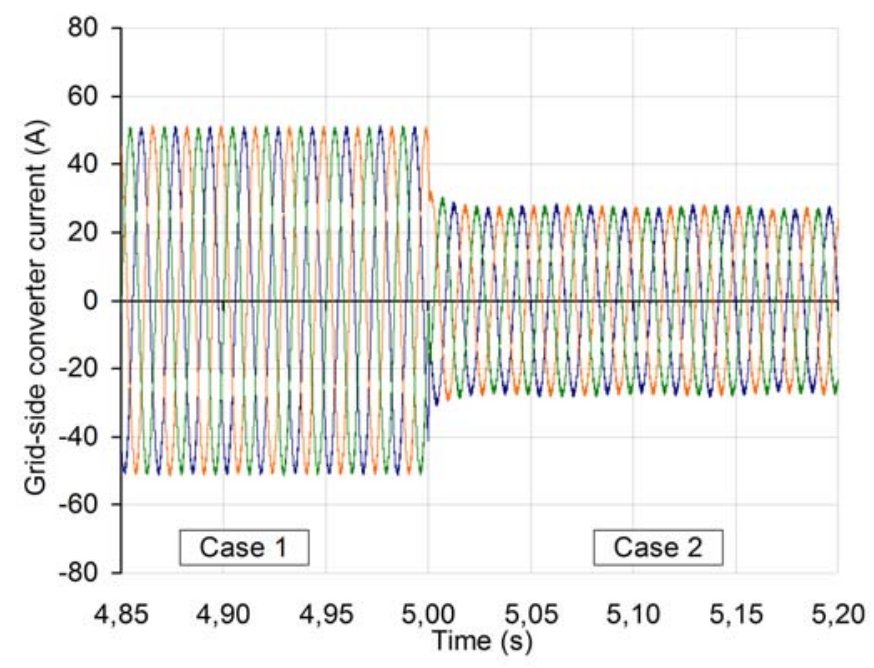

Fig. 9. Grid-side current for case 1 and 2

The power winding current is not much affected by the control strategy as can be seen in Fig. 8 .

Fig. 10 shows the voltage and current in the grid for the phase A and can be observed that a unity power factor is maintained in both cases.

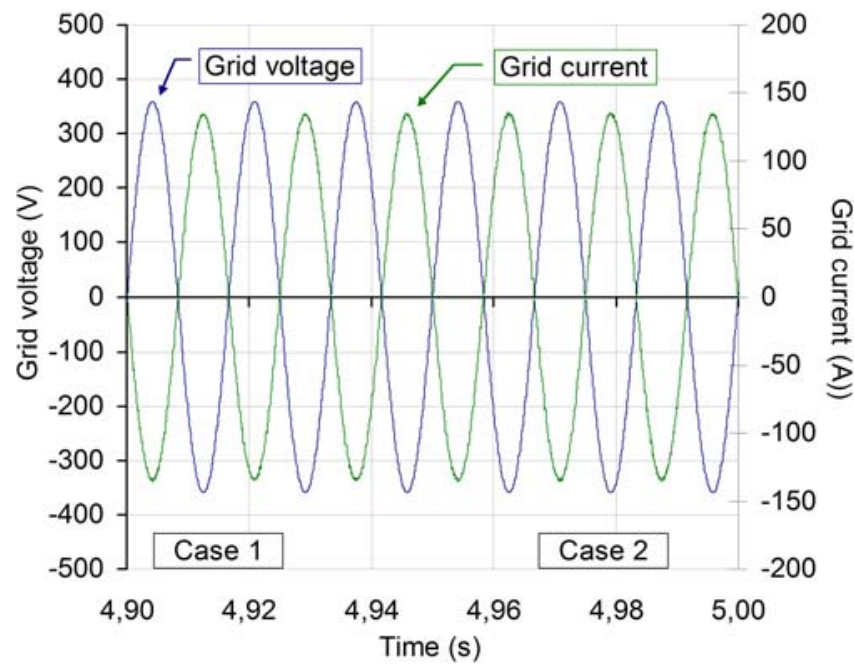

Fig. 10. Voltage and Current Grid for cases 1 and 2.

The following results (Figs. 11, 12, 13, and 14) correspond to case 1 where both converters are regulating the grid power factor. In this example, the wind speed varies linearly from $6.5 \mathrm{~m} / \mathrm{s}$ up to $12 \mathrm{~m} / \mathrm{s}$, which corresponds to the generator speed varying from $252 \mathrm{rpm}$ to $468 \mathrm{rpm}$, in a time interval of 20 s. Fig. 11 shows the current in the auxiliary winding. Examining this figure it is apparent the converter must be designed for the largest value of the auxiliary winding current that occurs at the upper speed limit.

The active, reactive and apparent powers were measured and are shown in Figs. 12, 13 and 14. They confirm the high reactive power of the BDFCIG in the generator speed range. In Fig. 14, can be noted that the rating of the auxiliary-side converter increase with the speed range of the generator. In $\omega_{\mathrm{r}}=\omega_{\text {sync }}$ although the lower apparent power of the auxiliary side converter, the current of the both converter are equals. The simulations results show that the two converters can operate dividing reactive power with the same current value in all generator speed range.

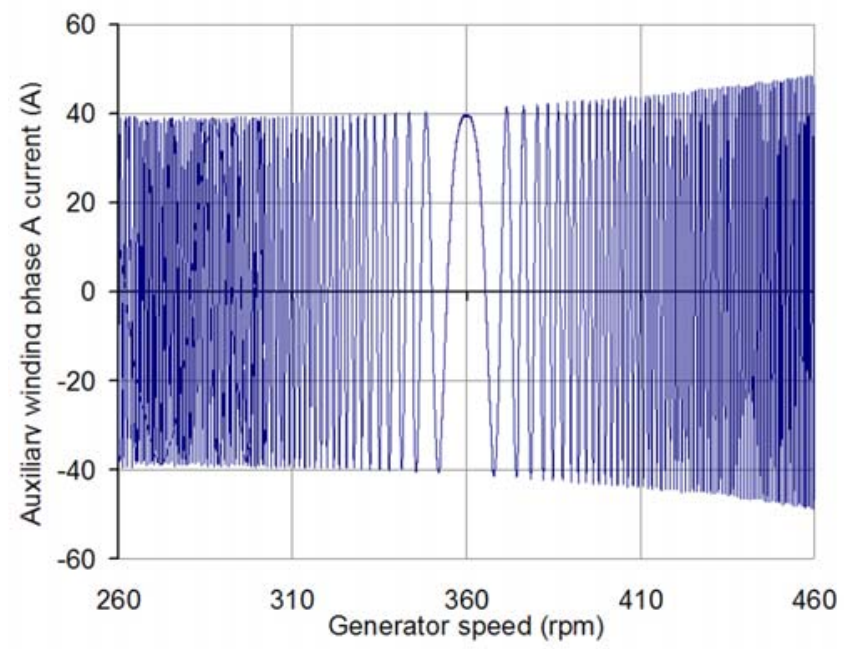

Fig. 11. Phase A current in the auxiliary winding.

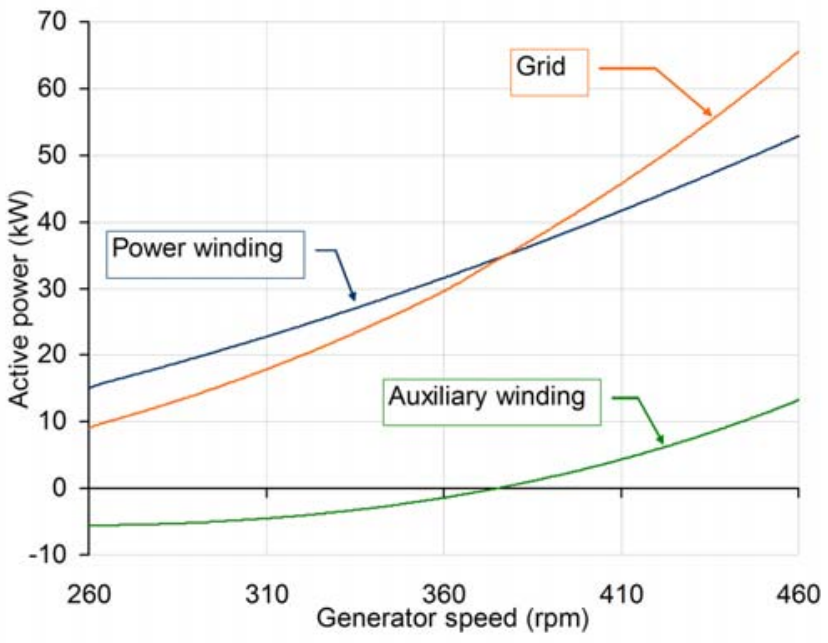

Fig. 12. Active power at the power winding, auxiliary winding and grid.

\section{CONCLUSION}

In this paper the vector control of the BDFIG using a rotating reference frame fixed on the power winding flux was implemented in Matlab/Simulink/SymPowerSystems. It has been shown that the control algorithm of the auxiliary-side and grid-side converters can control the active and reactive power independently. The reactive power control of the grid- 
side and auxiliary-side converters can be used to control the reactive power in power windings and the grid, respectively.

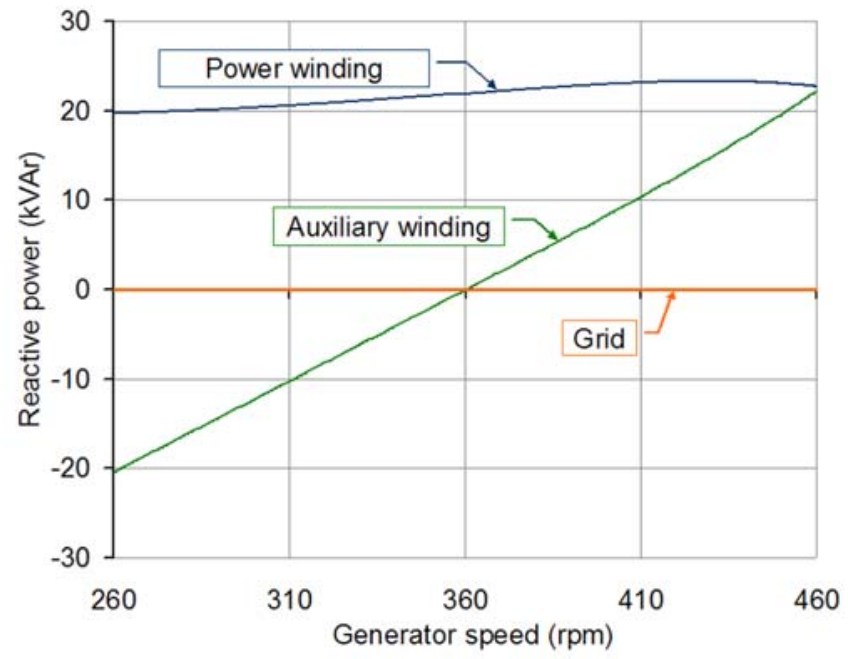

Fig. 13. Reactive power at the power winding, auxiliary winding and grid.

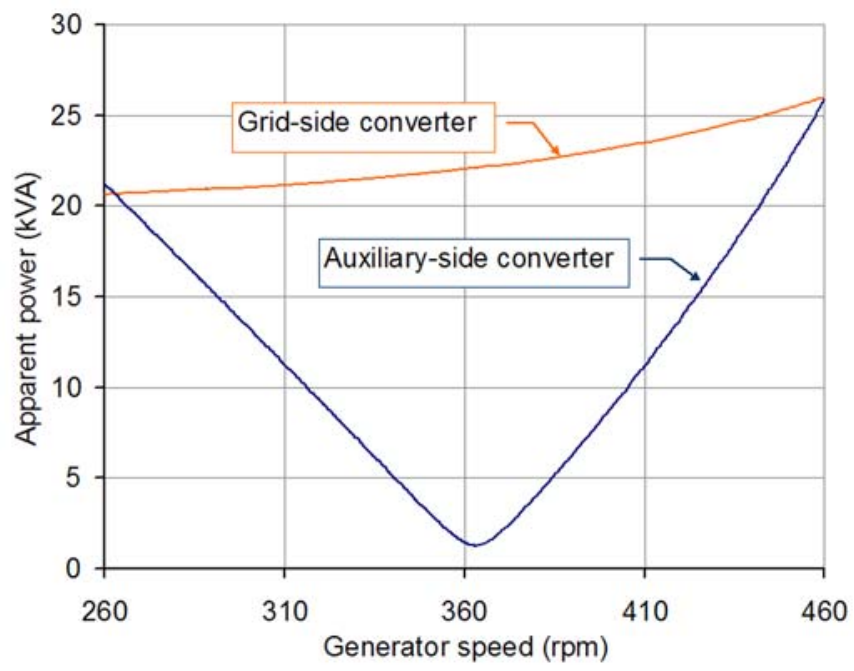

Fig. 14. Apparent power of the Auxiliary and Grid-side converter.

Two control strategies were presented. The first one involves both converters in the regulation of the grid powerfactor and therefore they should have the same rating. The other one involves only the auxiliary-side converter in the grid power factor control. The main differences concerning the converters are:

- $\quad$ in the first case both converters have the same rating;

- in the second case the rating of the auxiliary-side converter is $28 \%$ larger and the rating of the grid-side converter is only $53 \%$ of their ratings in the first case.

However, if the ratings of the two converters are added the result is almost the same in both two cases, meaning that possibly their total cost would be similar.

The efficiency in case 1 is a little higher (95.2\%) than in case 2 (93.9\%) not considering the generator iron losses and the mechanical losses.
In view of these conclusions, the decision about the power factor regulation strategy is not evident requiring further analysis.

\section{REFERENCES}

[1] R. Pena, J. C. Clare, G.M Asher, “Doubly fed induction generator using back-to-back PWM converter and its application to variable-Speed wind-energy generation.” IEE Proc.-Electr. Power Appl., Vol. 143, No. 3, May 1996.

[2] R. Spée, S. Bhowmik, and J. H. R. Enslin, "Novel control strategies for variable-speed doubly fed wind power generation systems,” Renewable Energy, vol. 6, no. 8, pp. 907-915, 1995.

[3] S. Williamson, A. C. Ferreira, A. K. Wallace, "Generalized theory of brushless doubly-fed machine Part 1: Analysis," IEE Proc. - Electric Power Applications, Vol. 144, No. 2, pp. 111-122, Mar. 1997.

[4] S. Williamson, A. C. Ferreira and A. K. Wallace, "Generalized theory of brushless doubly-fed machine Part 2: Model verification and performance,” IEE Proc. Electric Power Applications, Vol. 144, No. 2, pp. 123129, Mar. 1997.

[5] S. Bhowmik , R. Spée and J. H. R. Enslin, "Performance Optimization for doubly fed wind power generation systems”, IEEE Transactions on Industry Applications, v 35, No 4, Jul/Aug, pp 949-958, 1999

[6] F. Rüncos, R. Carlson, A.M. Oliveira, P. Kuo-Peng, N. Sadowski, "Performance analysis of a brushless doublé fed cage induction generator", Nordic Wind Power Conference, 1/2 March 2004, Göeteborg, Sweden.

[7] H. Shoudao; Y. Wang, Y.Yaonan,; G. Ren, “Active and reactive power control for brushless doubly-fed machine." Power Electronics and Motion Control Conference, 2004. IPEMC 2004. The 4th International Volume 2 14-16 Aug. 2004 Page(s):640 - 644 Vol.2

[8] J. Poza, E. Oyarbide, D. Roye, "New vector control algorithm for brushless doubly-fed machines.” IECON 02 Industrial Electronics Society, IEEE 2002 28th Annual Conference of theVolume 2, 5-8 Nov. 2002 Page(s):1138 - 1143 vol.2

[9] L. Xu and C.Wei, "Torque and reactive power control of a doubly fed induction machine by position sensorless scheme,” IEEE Trans. Ind. Appl.,vol. 31, no. 3, pp. 636642, May/Jun. 1995.

[10]B. Hopfensperger, D. J. Atkinson, and R. A. Lakin, "Stator-flux-oriented control of a doubly-fed induction machine with and without position encoder," Proc. Inst. Elect. Eng., vol. 147, pp. 241-250, Jul. 2000

[11]Y. Tang and L. Xu, "Flexible active and reactive power control strategy for a variable speed constant frequency generating system,” IEEE Trans. Power Electron., vol. 10, no. 4, pp. 472-478, Jul. 1995.

[12]J. B. Ekanayake, L. Holdsworth, X. Wu, N. Jenkins, "Dynamic modeling of doubly fed induction generator wind turbines”, IEEE Trans. On Power Systems, Volume: 18, Issue: 2, May 2003, Pages: 803 - 809. 
[13]I. Cadirci, M. Ermis, “Double-output induction generator operating at subsynchronous and supersynchronous speeds: steady-state performance optimization and windenergy recovery”, IEE Proceedings B, Volume: 139, Issue: 5, Sept. 1992, Pages: 429 - 442.

[14]C. Abbey, G. Joos, "Optimal reactive power allocation in a wind powered doubly-fed induction generator." Power Engineering Society General Meeting, 2004. IEEE6-10 June 2004 Page(s):1491 - 1495 Vol.2

[15]A. Petersson, L. Harnefors, T. Thiringer, "Evaluation of current control methods for wind turbines using doublyfed induction machines." Power Electronics, IEEE Transactions on Volume 20, Issue 1, Jan. 2005 Page(s):227 - 235.

[16]Y. Zhenyu, D. Figoli, “AC Induction Motor Control Using Constant V/Hz Principle and Space-Vector PWM Technique With TMS320C240.” Texas Instruments Literature umber SPRA284.

[17]D. Seyoum, C. Grantham and M. F. Rabman. "Simplified Flux Estimation for Control Application in Induction Machines". Electric Machines and Drives Conference, 2003. IEMDC'03. IEEE International Volume 2, 1-4 June 2003 Page(s):691 - 695 vol.2.

\section{APPENDIX}

\section{GENERATOR DATA}

The results presented in this paper concern a prototype with the following characteristics:

- Main stator winding: $75 \mathrm{~kW}, 254 / 440 \mathrm{~V}, 12$ poles, $60 \mathrm{~Hz}$, concentric, three-phase , two layers, connection $2 \Delta / 2 \mathrm{Y}, 144$ slots;

- Auxiliary stator winding: 25 kW, 690/1200 V, 8 poles, $60 \mathrm{~Hz}$, concentric, three-phase , two layers, connection $2 \Delta / 2 \mathrm{Y}$, 144 slots.

- Rotor winding: concentric, 10 poles, 11 slots per pole (Fig. A.1)

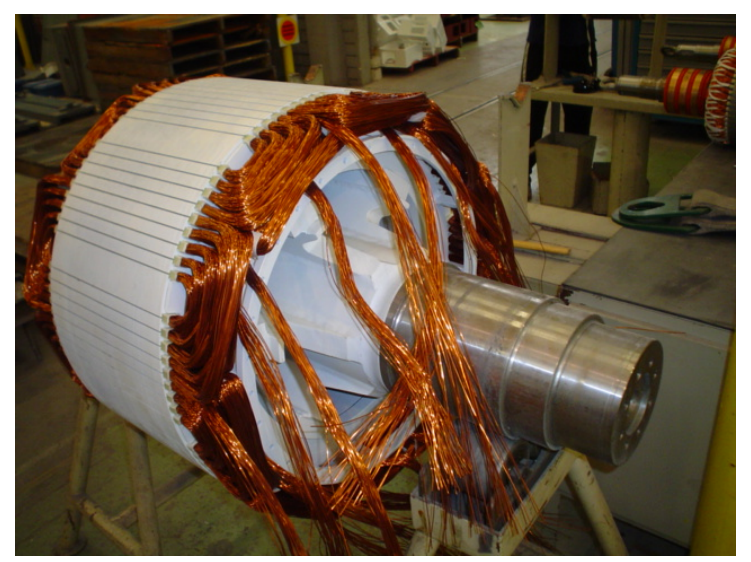

Fig. A.1 - Picture of the 'wounded cage'.

\section{BIOGRAPHIES}

Hélio Voltolini was born in Nova Trento, Santa Catarina, Brazil, on November 13, 1964. He received the B.C.E.E. degree from the Federal University of Santa Catarina, Florianópolis, Brazil, in 1990, and the M.S.E.E. degree from same University in 1995. His major field of study is electrical machines, adjustable speed drives and power electronics applications.

Since 1996 he joined the Electronic Department of the CEFET-PR - Brazil as Professor. Since 2003 he is with the Electrical Engineering Department, Federal University of Santa Catarina, Brazil preparing his Doctor thesis.

Renato Carlson was born in Porto Alegre, Brazil, on July 31, 1943. He received the B.C.E.E. degree from the Federal University of Rio Grade do Sul, Porto Alegre, Brazil, in 1969, the M.S.E.E. degree from the Federal University of Santa Catarina, Brazil, in 1973, and the D.Eng. degree from the University Paul Sabatier, Toulouse, France, in 1977. His major field of study is electrical machines and drives.

In 1970, he joined the staff of the Electrical Engineering Department, Federal University of Santa Catarina, Brazil, where he has been a Professor of electrical engineering until 1998. He has been Vice-President for Graduate Studies and Research at this university from 1996 up to 1998 when he retired. From 1989 to 1990, he was with the Laboratoire d'Electrotechnique et d'Electronique de Puissance of the Institut National Polytechnique de Toulouse, France, for a sabbatical year, obtaining at this time the Diplôme d'Habilitation à Diriger des Recherches.

Prof. Carlson is a member of the IEEE since 1980. He is now a Senior Member of the IEEE.

Fredemar Rüncos was born in Ilhota, Santa Catarina, Brazil, on May 24, 1952. He received the B.C.E.E. and Physics degrees from the Federal University of Paraná, Curitiba, Brazil, in 1980, the M.S.E.E. degree from the Federal University of Santa Catarina, Brazil, in 2002, and working to obtain his D.Eng. degree from the Federal University of Santa Catarina, Brazil, in 2005. His major field of study is electrical machines.

In 1990 he became the manager of the Product Engineering Department of WEG Industries - Máquinas, Jaraguá do Sul, Santa Catarina, Brazil, for large rotating electrical machines. In 1994, he joined the staff of the Engineering Department, of University Center of Jaraguá do Sul, Santa Catarina, Brazil, where he is a Professor of physics and electromagnetic theory.

Prof. Rüncos is in the present moment researching together with Federal University of Santa Catarina for developing a method to analyze the performance and vibration, design criteria and control of a brushless double fed induction machine. 